\title{
Modelling the effect of carbon on deformation behaviour of twinning induced plasticity steels
}

\author{
Mingxin Huang • Olivier Bouaziz • David Barbier • \\ Sebastien Allain
}

Received: 15 April 2011 / Accepted: 7 June 2011/Published online: 16 June 2011

(C) The Author(s) 2011. This article is published with open access at Springerlink.com

\begin{abstract}
In this article, a physical model describing the deformation behaviour of Twinning Induced Plasticity (TWIP) steels has been extended to include the effect of carbon content. The experimental validation and the analysis show that carbon mainly controls the maximum number of dislocations piled up at the twin boundary, resulting in the increase of back-stresses (i.e. kinematic hardening) and therefore the work hardening rate. This explanation seems to be in agreement with recent TEM observations.
\end{abstract}

\section{Introduction}

It is now well known that among all the various possible deformation modes in austenitic steels, Twinning Induced Plasticity (TWIP) results in a significant increase of work hardening rate even at large plastic strains [1, 2]. It has been proposed that deformation twins increase the work hardening rate by acting as planar obstacles for gliding dislocations. During the last ten years, physical based models have been developed specifically for high manganese TWIP steels [3-7] to:

M. Huang $(\bowtie)$

Department of Mechanical Engineering, The University of Hong

Kong, Pokfulam Road, Hong Kong, China

e-mail: mxhuang@hku.hk

O. Bouaziz $\cdot$ D. Barbier $\cdot$ S. Allain

Arcelor Mittal Research, Voie Romaine-BP 30320,

57283 Maizières-lès-Metz Cedex, France

O. Bouaziz

Centre des Matériaux, Mines ParisTech, CNRS-UMR7633,

BP 87, 91003 Evry cedex, France
- compute the stacking fault energy as a function of the chemical composition,

- describe the interaction between dislocation glide and deformation twinning,

- predict the resulting high work hardening rate due to dynamic microstructure refinement (dynamic HallPetch effect).

In addition, it has also been shown that high manganese austenitic TWIP steels exhibit a strong Bauschinger effect (i.e. kinematic hardening) as observed by experiments by Bouaziz et al. [8] and Gutierrez-Urrutia et al. [9], which should be incorporated in physical models predicting work hardening behaviour [10-12]. Thus, TWIP effect can be also seen as a 'dynamic composite' where the volume fraction of the reinforcement (twins) increases continuously with the plastic strain [13].

Although it was possible to apply the existing modelling to describe accurately the behaviour of a TWIP steel with a given chemical composition, it seems much more difficult to capture the evolution of the work hardening rate as a function of the chemical composition [14, 15]. Recent experiments show that the stacking fault energy is not the only parameter controlling the mechanical twinning behaviour and the work hardening rate of TWIP steels. For Fe-Mn-C TWIP steels with similar stacking fault energy, it is shown that the carbon content can affect the mechanical twinning behaviour and the work hardening rate [14]. For instance, Fe-30 wt $\% \mathrm{Mn}$ has similar stacking fault energy with $\mathrm{Fe}-22$ wt $\% \mathrm{Mn}-0.6 \mathrm{wt} \% \mathrm{C}$. However, Fe-30 wt $\% \mathrm{Mn}$ does not have significant mechanical twinning as demonstrated by TEM study showing a well-developed dislocation cells (Fig. 1a). On the contrary, extensive mechanical twinning was observed in Fe-22 wt $\% \mathrm{Mn}-0.6 \mathrm{wt} \% \mathrm{C}$ (Fig. 1b). The effect of $\mathrm{C}$ on the work hardening rate of 
Fig. 1 a Bright-field image of $\mathrm{Fe}-30 \mathrm{Mn}$ deformed up to $20 \%$ in tension showing welldeveloped dislocation cell-like structure and b Dark-field image of $\mathrm{Fe}-22 \mathrm{Mn}-0.6 \mathrm{C}$ after $50 \%$ strain and showing extensive mechanical twinning [14]

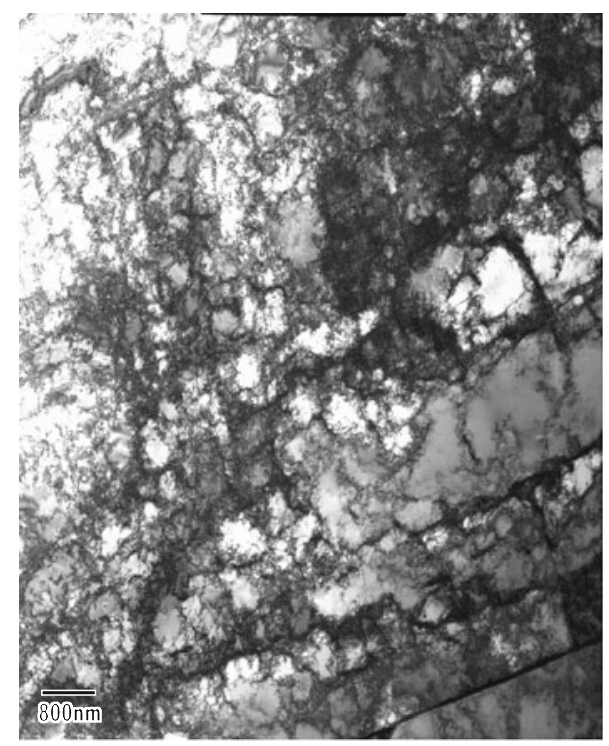

(a)

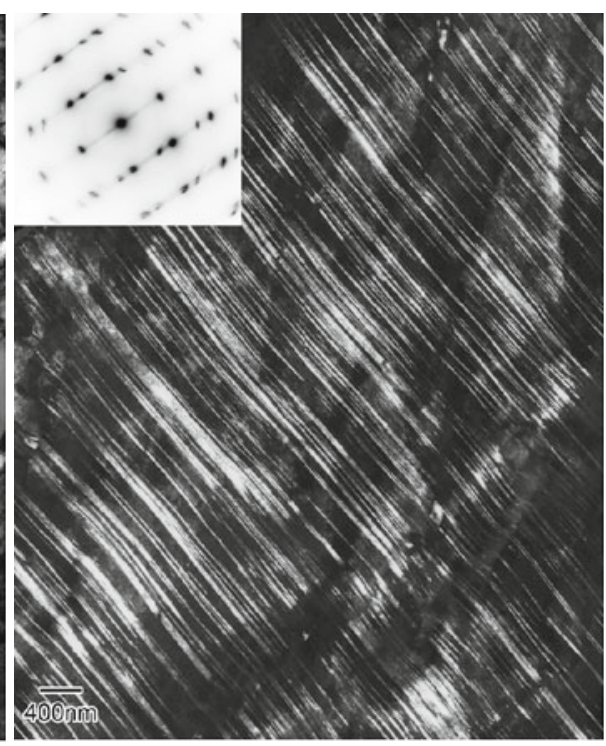

(b)
TWIP steels is further confirmed by another TEM study, which shows that one $\mathrm{Fe}-\mathrm{Mn}-\mathrm{C}$ TWIP steel and one $\mathrm{Fe}-$ $\mathrm{Mn}-\mathrm{Si}-\mathrm{Al}$ TWIP steel with similar twin volume fraction exhibit very different work hardening rate [15]. This TEM study suggests that carbon content controls the dislocation structure stored at the twin boundary, resulting in different work hardening rates.

The aim of the present study is to capture the effect of carbon on the work hardening rate of $\mathrm{Fe}-\mathrm{Mn}-\mathrm{C}$ TWIP steels by extending a physical model proposed previously [8]. In this purpose, the mechanical behaviours of several TWIP steels with different $\mathrm{Mn}$ and $\mathrm{C}$ contents are analysed. The $\mathrm{Mn}$ and $\mathrm{C}$ composition are selected to avoid the formation of deformation induced martensite.

\section{Model}

During the plastic deformation of TWIP steels, the flow stress $\sigma$ is composed of three parts [8]:

$\sigma=\sigma_{0}+\sigma_{\mathrm{f}}+\sigma_{\mathrm{b}}$,

where $\sigma_{0}$ is the friction stress due to solid solution, $\sigma_{\mathrm{f}}$ is related to isotropic hardening induced by dislocations and $\sigma_{\mathrm{b}}$ is the back-stress related to kinematic hardening. $\sigma_{\mathrm{f}}$ can be expressed by the Taylor relation:

$\sigma_{\mathrm{f}}=\alpha M \mu b \sqrt{\rho}$,

where $\alpha$ is a constant describing the interactions between dislocations, $M$ is the Taylor factor, $\mu$ is the shear modulus, $b$ is the magnitude of Burgers vector and $\rho$ is the average dislocation density.
The total plastic strain $\varepsilon$ in TWIP steels is induced by dislocation glide and mechanical twinning, which is expressed by the mixture law [8]:

$d \varepsilon=(1-F) d \varepsilon_{\mathrm{g}}+M \gamma_{\mathrm{t}} d F$,

where $F$ is the twin volume fraction, $\varepsilon_{\mathrm{g}}$ is the strain induced by dislocation glide, $\gamma_{t}=\sqrt{2} / 2$ is the shear strain induced by twinning.

The back stress $\sigma_{\mathrm{b}}$ is expressed as [8]

$\sigma_{\mathrm{b}}=M \frac{\mu b}{L} n$,

where $L$ is the geometrical length scale of the microstructure and $n$ is the number of dislocation piled up at the boundaries (twin or grain boundaries). $L$ is expressed as

$\frac{1}{L}=\frac{1}{d}+\frac{1}{t}$,

where $d$ is the grain size and $t$ is the mean twin distance. According to the stereological analysis of Fullman [16], $t$ is linked to the twin volume fraction $F$ and the twin thickness $e$ (assumed being a constant):

$t=\frac{2 e(1-F)}{F}$.

The number of dislocations piled up at the boundary, $n$, is evolving with deformation as $[8,17]$

$\frac{d n}{d \varepsilon_{\mathrm{g}}}=\frac{\lambda}{b}\left(1-\frac{n}{n_{0}}\right)$

where $\lambda$ is the mean spacing between slip bands and $n_{0}$ is the maximum number of dislocations piled up at the boundaries. 
The evolution of the dislocation density can be described by the modified Kocks-Mecking model [17, 18] as

$\frac{d \rho}{d \varepsilon_{\mathrm{g}}}=M\left(\frac{1-n / n_{0}}{b L}+\frac{k}{b} \sqrt{\rho}-f \rho\right)$,

where $k$ and $f$ are constants. The first two terms in the bracket of Eq. 8 describe the dislocation generation while the third term is the dislocation annihilation.In the absence of a valid physical expression, an empirical law was chosen to describe the evolution of twin volume fraction $F$, which can be expressed as

for $\varepsilon>\varepsilon_{\text {init }}, F=F_{0}\left(1-\mathrm{e}^{-\beta\left(\varepsilon-\varepsilon_{\text {init }}\right)}\right)^{m}$

where $\varepsilon_{\text {init }}$ is the critical strain at which mechanical twinning begins, $F_{0}$ is the maximum volume fraction of mechanical twins, $\beta$ and $m$ are constants. Soulami et al. [7] recently also proposed a model to predict the evolution of twin volume fraction, which is similar to the models used for the martensitic transformation in TRIP steels.

\section{Results and discussion}

Figure 2 presents the experimental results of tension at room temperature of the selected TWIP steels with different chemical composition. The mean grain size of all materials is about $20 \mu \mathrm{m}$. The model predictions, Fig. 3, show good agreement with experimental observations. Referred to the model, all parameters used in the present calculation are shown in Table 1 . Except for $n_{0}$ (the maximum number of dislocations which can pile up at the boundaries) other parameters used in the calculation are the same for all the alloys. The chemical composition and $n_{0}$ value for each alloy are also indicated in Fig. 3.

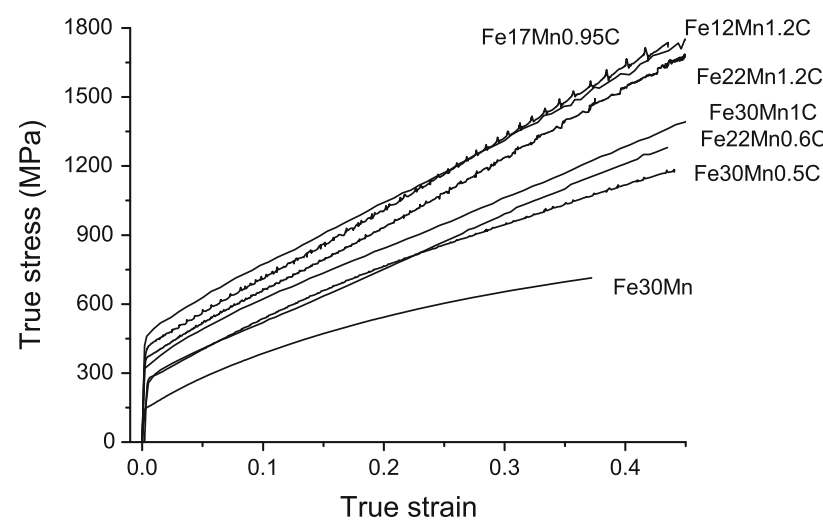

Fig. 2 Tensile behaviour of TWIP steels for a wide range carbon and manganese contents ( $\mathrm{Fe}-30 \mathrm{Mn}-1 \mathrm{C}$ : data from the literature [19], $\mathrm{Fe}-$ 12Mn-1.2C: data from the literature [20], Fe-30Mn: data from [21], other data from the literature [14]). The chemical composition is in weight percent
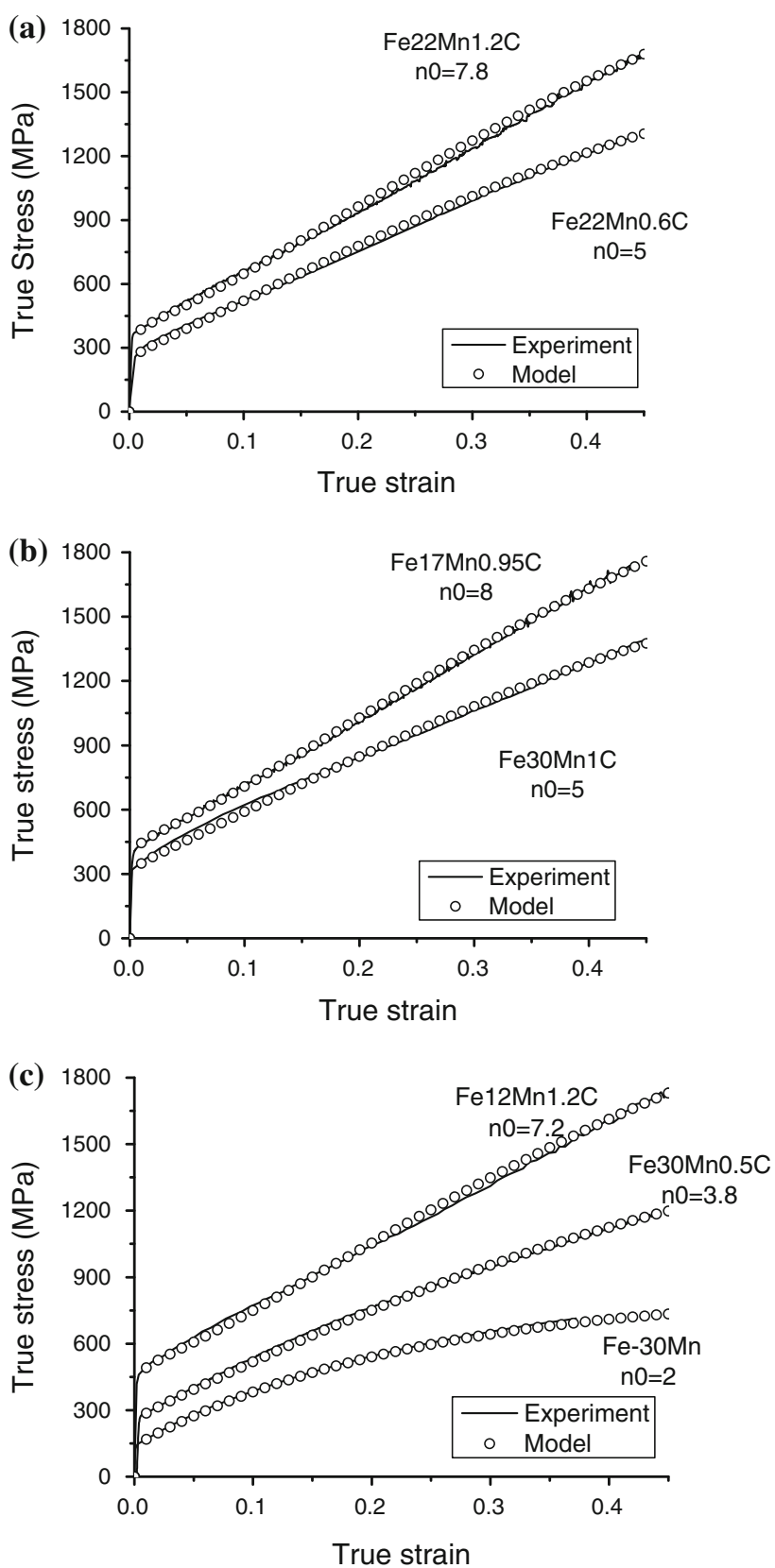

Fig. 3 True stress-true strain curves of TWIP steels for a wide range carbon and manganese contents deformed at room temperature and a strain rate between $10^{-4}$ and $10^{-3} \mathrm{~s}^{-1}$

It is noted that $\mathrm{Fe}-30 \mathrm{Mn}$ alloy (in Fig. 3c) does not have any twins during deformation as shown by TEM (Fig. 1b). In the current model prediction, the twin volume fraction is therefore set to zero for $\mathrm{Fe}-30 \mathrm{Mn}$ alloy. It is worth noting that the model can predict well the stress-strain behaviour by using the same $k$ (forest hardening) and $f$ (dynamic recovery) value for all alloys in Fig. 3, which suggests that the chemical composition has very little effect on the forest hardening and dynamic recovery. 
Table 1 Parameters used in the current calculation

\begin{tabular}{lll}
\hline Parameters & Physical meaning & Value \\
\hline$\mu$ & Shear modulus & $65 \mathrm{GPa}$ \\
$b$ & Burgers vector & $2.5 \times 10^{-10} \mathrm{~m}$ \\
$M$ & Taylor factor & 3.06 \\
$\alpha$ & Mean dislocation strength & 0.4 \\
$k$ & Forest hardening & 0.025 \\
$f$ & Dynamic recovery & 2.8 \\
$\lambda$ & Mean spacing between slip bands & $1266 b$ \\
$F_{0}$ & Maximum volume fraction of Twins & 0.2 \\
$e$ & Twin mean thickness & $30 \mathrm{~nm}$ \\
$\varepsilon_{\text {init }}$ & The critical strain at which twinning & 0.03 \\
$\beta$ & begins & 3 \\
$m_{0}$ & - & 2
\end{tabular}

Only three parameters $\left(k, f\right.$ and $\left.\varepsilon_{\text {init }}\right)$ used in the current calculation are slightly different to the ones used in the literature [8]. Other parameters are obtained from the literature [8]

It can be seen that the effect of chemical composition on the work hardening behaviour of TWIP steels can be well captured by the model by fitting one physical parameter $n_{0}$, i.e. the chemical composition dependence of $n_{0}$. Figure $4 \mathrm{a}$ demonstrates the relationship between $n_{0}$ and $C$ content. $n_{0}$ seems to increase with the $\mathrm{C}$ content as shown in Fig. 4a. This can be explained by the fact that the intrinsic properties of the mechanical twins are related to the $\mathrm{C}$ content, which has been confirmed by TEM using two TWIP steels namely Fe-28Mn3.5Si-2.8Al and $\mathrm{Fe}-20 \mathrm{Mn}-1.2 \mathrm{C}$ [15]. The TWIP steel with $\mathrm{C}$ content shows the mechanical twins full of sessile dislocations, which are very strong obstacles for dislocation pile-up, while the TWIP steel without $\mathrm{C}$ content produces mechanical twins without any sessile dislocation. Thus, it could be expected that higher $\mathrm{C}$ content could lead to more sessile dislocations in mechanical twins which are stronger for dislocation pile-up. Therefore, $n_{0}$ increases with the $\mathrm{C}$ content.

However, the Mn content seems to have very little effect on $n_{0}$, which is similar to the effect of $\mathrm{C}$ and $\mathrm{Mn}$ on the friction stress as reported in the literature [14]. It is also interesting to illustrate that $n_{0}$ seems to increase with $\sigma_{0}$ (Fig. 4b). The reason why $n_{0}$ increases with $\sigma_{0}$ could be explained as a TWIP steel with a higher $\sigma_{0}$ value may exhibit stronger twins which are more effective as obstacles for dislocation movement as demonstrated by the recent TEM study [15].

\section{Summary}

The present study extends a previous physical model to include the effect of carbon content on the work hardening
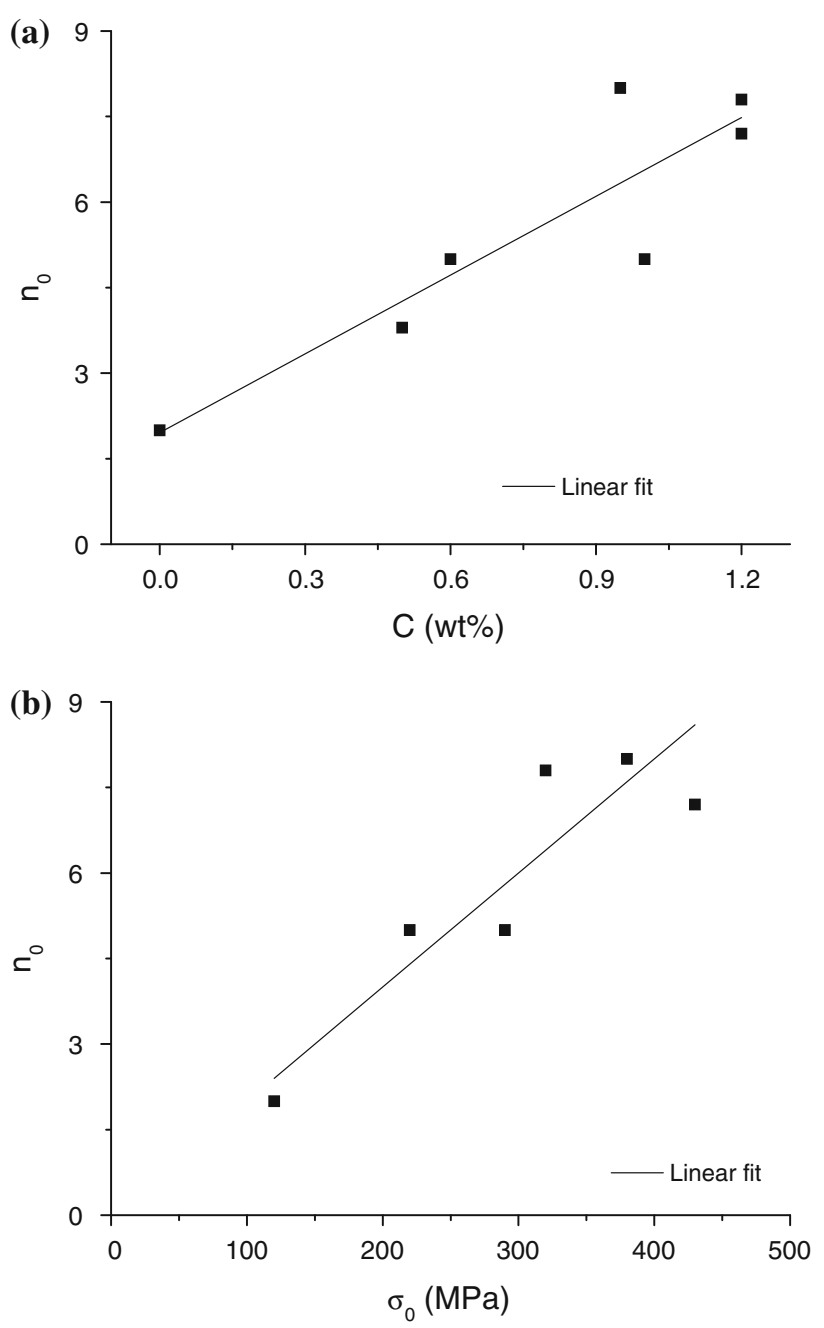

Fig. 4 a Relation between $n_{0}$ and C content; b relation between $n_{0}$ and $\sigma_{0}$

behaviour of a wide range of $\mathrm{Fe}-\mathrm{Mn}-\mathrm{C}$ TWIP steels. The model captures well the effect of carbon by adjusting one physical parameter $n_{0}$ meaning that carbon mainly controls the maximum number of dislocations piled up at the twin boundary. Higher carbon content leads to more dislocations piled up at the twin boundary, resulting in higher backstresses (i.e. kinematic hardening) and therefore higher work hardening rate. This analysis seems to be in agreement with recent TEM observations [15], but future researches are required to provide more insight information to understand such a dependence.

Acknowledgements $\mathrm{MH}$ gratefully acknowledges the financial support from the University Research Committee of The University of Hong Kong (Project code: 201009159012).

Open Access This article is distributed under the terms of the Creative Commons Attribution Noncommercial License which permits any noncommercial use, distribution, and reproduction in any medium, provided the original author(s) and source are credited. 


\section{References}

1. Remy L (1976) PhD Thesis. Orsay University, Paris

2. Scott C, Allain S, Faral M, Guelton N (2006) Revue De Metallurgie-Cahiers D Informations Techniques 103:293-302

3. Allain S, Chateau JP, Bouaziz O (2004) Mater Sci Eng A 387-389:143-147

4. Allain S, Chateau JP, Bouaziz O, Migot S, Guelton N (2004) Mater Sci Eng A 387-389:158-162

5. Bouaziz O, Guelton N (2001) Mater Sci Eng A 319-321:246-249

6. Nakano J, Jacques PJ (2010) Calphad 34:167-175

7. Soulami A, Choi KS, Shen YF, Liu WN, Sun X, Khaleel MA (2011) Mater Sci Eng A 528:1402-1408

8. Bouaziz O, Allain S, Scott C (2008) Scripta Mater 58:484-487

9. Gutierrez-Urrutia I, del Valle J, Zaefferer S, Raabe D (2010) J Mater Sci 45:6604-6610

10. Das D, Chattopadhyay P (2009) J Mater Sci 44:2957-2965

11. Zhang W, Wu J, Wen Y, Ye J, Li N (2010) J Mater Sci 45:3433-3437
12. Lopes W, Corrêa E, Campos H, Aguilar M, Cetlin P (2009) J Mater Sci 44:441-448

13. Gil Sevillano J (2009) Scripta Mater 60:336-339

14. Bouaziz O, Zurob H, Chehab B, Embury JD, Allain S, Huang M (2011) Mater Sci Technol 27:707-709

15. Idrissi H, Renard K, Schryvers D, Jacques PJ (2010) Scripta Mater 63:961-964

16. Fullman RL (1953) Trans AIME 197:447

17. Sinclair CW, Poole WJ, Brechet Y (2006) Scripta Mater 55:739-742

18. Kocks UF, Mecking H (2003) Prog Mater Sci 48:171-273

19. Lai HJ, Wan CM (1989) Scripta Metallurgica 23:179-182

20. Bayraktar E, Khalid FA, Levaillant C (2004) J Mater Process Technol 147:145-154

21. Liang X, McDermid JR, Bouaziz O, Wang X, Embury JD, Zurob HS (2009) Acta Mater 57:3978-3988 